\title{
The Variations in the Altitudes Between the Sea Level and Ajloun Impact Heart Variables, but not Angiotensin Ii
}

\author{
Jehan Fayez Sweis \\ Reema Kamal Haddad \\ Abdallah T Salmoneh \\ Rabia Jamil Aljabra \\ Taghreed A Alrefai \\ Royal Medical Services, Jordan \\ Mahmoud abu abeeleh \\ The University of Jordan, Jordan \\ Jaafar abu abeeleh \\ Royal Medical Services, Jordan \\ Mustafa Ahmad Al-Shehabat \\ Department of Physiology, Faculty of Medicine, Jordan University of \\ Science and technology, Jordan \\ Ahed J Alkhatib \\ Jordan University of Science and technology, Jordan \\ doi: 10.19044/esj.2016.v12n36p446 URL:http://dx.doi.org/10.19044/esj.2016.v12n36p446
}

\begin{abstract}
Background: hypertension affects many people worldwide and it is highly prevalent in Jordan. Living at different areas with different attitudes may have impacts in hypertension.

Study objectives: to identify the prevalence of hypertension in two areas in Jordan with different attitudes and to determine the impact of attitudes in hypertension and angiotensin II to be able to determine the appropriate antihypertensive drug for such population.

Methodology: a cross-sectional study design was conducted to collect data from participants. The study included 1000 participants, 500 from each area. A constructed questionnaire was used in this study. Blood samples were taken from participants to assay for angiotensin II. Blood pressure was measured for all patients. Data was analyzed using SPSS version 20. Data was presented as means, frequencies, percentages. The relationship between variables was examined using independent T-test. Significance was considered at alpha level $<0.05$.
\end{abstract}


Study findings: the main findings of the present study were that cardiac variables including SPS, DBP, MBP, and pulse were significantly higher in Ajloun compared with the Sea level area $(\mathrm{p}=0.001)$. This is also applied for PCV. The mean concentration of angiotensin II in the Sea level was 11.21士 $6.05 \mathrm{pg} / \mathrm{ml}$, and this was lower than that in the Ajloun area 12.08 \pm 5.19 , but this mean difference was not statistically significant $(\mathrm{p}>0.05)$.

Conclusions: living in high altitude is associated with increased potential to have increased levels of cardiac parameters independently of the level of angiotensin II and the therapeutic options for patients with hypertension should be taken into account.

Keywords: Angiotensin II, blood pressure, altitude, Ajloun, the Sea level.

\section{Introduction}

In this study, there is an interest in exploring cardiac parameters among participants living in two areas with different altitudes. In Jordan, there is a diversity in environmental components including variations in altitudes.

Hypertension is considered as a significant cause of the total disease burden globally (Lim et al., 2012). Several studies have shown that hypertension is highly associated with cardiovascular diseases including stroke and ischemic heart disease (Stokes et al., 1989; Eckner, 2014).

Hypertension is considered as a bad predictor of heart disease (CDC, 2015). It has been estimated that about 67 million Americans are with high blood pressure among which are $36 \%$ have uncontrolled high blood pressure (Delacroix et al., 2014). The global prevalence of hypertension has been estimated to be $40 \%$ (Nwankwo et al., 2012).

It has been reported that both treatment and awareness of high blood pressure were not enough and this was demonstrated by the law of halves which means that only half of hypertensive patients were aware of their disease, and only half of them were treated, and of those who were treated achieved treatment goals (Eckner, 2014). Although the treatment of hypertension has lowered the events of cardiovascular system, but it is still believed that high blood pressure and hypertension can be improved further (Lindblad et al., 2011).

The present study is the first in Jordan to assess the level of hypertension parameters in different areas according to their altitudes. Accordingly, the objectives of the present study were to identify the prevalence of hypertension in two areas in Jordan with different attitudes and to determine the impact of attitudes in hypertension and angiotensin II to be able to determine the appropriate antihypertensive drug for such population. 


\section{Methods and subjects}

Study design: we conducted a cross sectional study to collect data from study participants within the same time frame.

\section{Study setting}

We conducted our study in two areas with different altitudes: the Sea level area and Ajloun area, Jordan.

\section{Study sample}

A total of 1000 participants were included in this study. Of them, 500 participants were included from each area. All participants were males, matched for age grouping, and they were apparently healthy.

\section{Data collection}

We collected and tabulated the data for each participant. The variables under investigation included blood pressure, weight, height, waist circumference, heart rate per minute, the level of angiotensin II, and packed cell volume (PCV).

\section{Data analysis}

We depended on SPSS version 20 to analyze the data. Data were represented as mean and standard deviation. The relations between variables were computed using independent $\mathrm{T}$ test. Significance was considered at alpha $<0.05$.

\section{Results}

Comparison between the Means and Standard Deviations of Blood Pressure and other Variables in the Sea Level and Ajloun

The data presented in table 1 showed the mean differences for some variables among participants in the two different study areas with different altitudes, Ajloun and the Sea level. Similar patterns of frequency were observed for the following variables: age, weight, height, BMI, and waist circumferences, and accordingly no significant differences were observed ( $>$ >0.05). On the other hand, it was interestingly found that all cardiac variables including SPS, DBP, MBP, and pulse were significantly higher in Ajloun compared with the Sea level area $(\mathrm{p}=0.001)$. This is also applied for PCV.

Table 1: Comparison between the Means and Standard Deviations of Blood Pressure and other Variables in the Sea Level and Ajloun.

\begin{tabular}{|r|r|r|r|}
\hline \multirow{2}{*}{ Variables } & Sea level & Ajloun & \multirow{2}{*}{ P value } \\
\cline { 2 - 3 } & Mean \pm std & Mean \pm std & \\
\hline
\end{tabular}




\begin{tabular}{|r|r|r|r|}
\hline Age & $17.60 \pm 0.51$ & $17.83 \pm 0.69$ & NS \\
\hline Weight/kg & $\mathbf{6 7 . 6 9} \pm \mathbf{8 . 7 0}$ & $\mathbf{6 7 . 3 7} \pm 10.76$ & NS \\
\hline Height/cm & $170.50 \pm 5.85$ & $169.51 \pm 7.42$ & NS \\
\hline BMI & $23.26 \pm 2.57$ & $23.42 \pm 3.22$ & NS \\
\hline Waist cir./cm & $76.38 \pm 6.00$ & $75.99 \pm 10.21$ & NS \\
\hline SBP/mmHg & $118.07 \pm 11.64$ & $\mathbf{1 2 5 . 7 4} \pm 10.01$ & $\mathbf{0 . 0 0 1}$ \\
\hline DBP/mmHg & $75.74 \pm 8.48$ & $\mathbf{7 9 . 6 2} \pm 8.43$ & $\mathbf{0 . 0 0 1}$ \\
\hline MBP/mmHg & $\mathbf{8 9 . 8 4} \pm 8.72$ & $\mathbf{9 4 . 9 5} \pm 8.03$ & $\mathbf{0 . 0 0 1}$ \\
\hline Pulse/minute & $79.07 \pm 6.46$ & $\mathbf{8 1 . 7 1} \pm 5.66$ & $\mathbf{0 . 0 0 1}$ \\
\hline PCV & $41.50 \pm 3.27$ & $45.27 \pm 2.18$ & $\mathbf{0 . 0 0 1}$ \\
\hline
\end{tabular}

Comparison between Angiotensin II Concentration in Ajloun and the Sea level Areas

As seen in table 2 and figure 1, the mean concentration of angiotensin II in the Sea level was $11.21 \pm 6.05 \mathrm{pg} / \mathrm{ml}$, and this was lower than that in the Ajloun area $12.08 \pm 5.19$, but this mean difference was not statistically significant $(\mathrm{p}>0.05)$.

Table 2: Comparison between Angiotensin II Concentration in Ajloun and the Sea level Areas

\begin{tabular}{|r|r|r|r|r|}
\hline Target Area & Mean \pm std & Target Area & Mean \pm std & P value \\
\hline Sea level & $\mathbf{1 1 . 2 1} \pm \mathbf{6 . 0 5}$ & Ajloun & $\mathbf{1 2 . 0 8} \pm \mathbf{5 . 1 9}$ & NS \\
\hline
\end{tabular}

\section{Discussion}

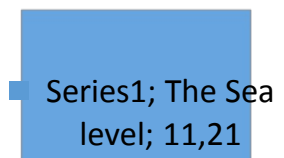

Series1; Ajloun;

12,08

Figure 1: the angiotensin level in the Sea level and Ajloun

The results of the present study did not show that the mean of heart readings pointed to hypertension in both study areas the Sea level and Ajloun. We think this may due to two factors: young age relatively at both areas and participants were chosen to be apparently healthy. Accordingly, our results are 
good to indicate the physiological status of heart parameters and to investigate the effect of altitude on these parameters.

The findings of our study indicated that heart parameters relating to hypertension including SPS, DBP, MBP, and pulse were significantly higher in Ajloun compared with the Sea level area $(\mathrm{p}=0.001)$. This is also applied for PCV. Actually, these findings reflected the effects of altitude on blood pressure. These findings are in line with other studies. At very high altitudes, where the quantity of oxygen in the air is greatly decreased, insufficient oxygen is transported to the tissues, and red cell production is greatly increased. In this case, it is not the concentration of red blood cells in the blood that controls red cell production but the amount of oxygen transported to the tissues in relation to tissue demand for oxygen. The principal stimulus for red blood cell production in low oxygen states is a circulating hormone called erythropoietin. In the absence of erythropoietin, hypoxia has little or no effect in stimulating red blood cell production. But when the erythropoietin system is functional, hypoxia causes a marked increase in erythropoietin production, and the erythropoietin in turn enhances red blood cell production until the hypoxia is relieved (Ganong, 1997; Hal, 2003; Guyton and Hall, 2006).

The level of angiotensin II, on the other hand was not significantly varied ( $p>0.05)$, but the trend was to have higher levels of angiotensin II in Ajloun than the Sea level area. Angiotensin is an oligopeptide in the blood that causes vasoconstriction, increased blood pressure, and release of aldosterone from the adrenal cortex. It is derived from the precursor molecule angiotensinogen, a serum globulin produced in the liver and it plays an important role in the renin-angiotensin-aldosterone system. Angiotensin was independently isolated in Indianapolis and Argentina in the late 1930s (as 'Angiotonin' and 'Hypertensin' respectively) and subsequently characterized and synthesized by groups at the Cleveland Clinic and Ciba laboratories in Basel, Switzerland (Basso and Terragno, 2001).

We think that the effect of altitude in this study may work independently from angiotensin II and other mechanisms need to be further investigated.

Conclusion: The findings of the present study showed that living in high altitudes is associated with the risk of developing hypertension and other related diseases. The angiotensin therapeutic options have to be taken in treating patients with hypertension in these areas.

\section{References:}

1. Basso N, Terragno NA (2001). History about the discovery of the renin-angiotensin system. Hypertension 38 (6): 1246-9. 
2. Centers for Disease Control and Prevention. (2015). Healthy People 2010: Final Review. Retrieved from August 04, 2014; Accepted November 20, 2014; Published November 25, 2014.

3. Delacroix S, Chokka RC, Worthley SG (2014) Hypertension: Pathophysiology and Treatment. J Neurol Neurophysiol 5:250. doi:10.4172/2155-9562.

4. Ganong, W (1997). Review of Medical Physiology. New Jersey: Simon \& Schuster Company, p.540,560

5. Guyton, Hall (2006). Textbook of Medical Physiology. Pennsylvania: Elsevier Saunders, p.161,164,204210,342,343.422.

6. Jenny Eckner (2014). High blood pressure - determinants and risks: Implications for treatment and prevention in a primary care setting. Master thesis, Department of Public Health and Community Medicine/ Primary Health Care Institute of Medicine Sahlgrenska Academy at University of Gothenburg.

7. Lim SS, Vos T, Flaxman AD, Danaei G, Shibuya K, Adair-Rohani $\mathrm{H}$, et al (2012). A comparative risk assessment of burden of disease and injury attributable to 67 risk factors and risk factor clusters in 21 regions, 1990-2010: a systematic analysis for the Global Burden of Disease Study 2010. Lancet, 380:2224-60.

8. Lindblad U, Ek J, Eckner J, Larsson CA, Guangliang S, Råstam L (2011). Prevalence, awareness, treatment and control of hypertension - rule of thirds in The Skaraborg Project. SJPHC, 30:88-94.

9. Nwankwo, Tatiana M.S.; Yoon, Sung Sug (Sarah) PhD., RN.; Burt, Vicki Sc.M., RN.; Gu, Quinping MD., PhD. Hypertension Among Adults in the United States: National Health and Nutrition Examination Survey, 2011-2012, October 2013. http://www.cdc.gov/nchs/data/databriefs/db133.htm

10. Stokes J 3rd, Kannel WB, Wolf PA, D'Agostino RB, Cupples LA (1989). Blood pressure as a risk for cardiovascular disease. Hypertension 13(5 suppl):I13-8. 